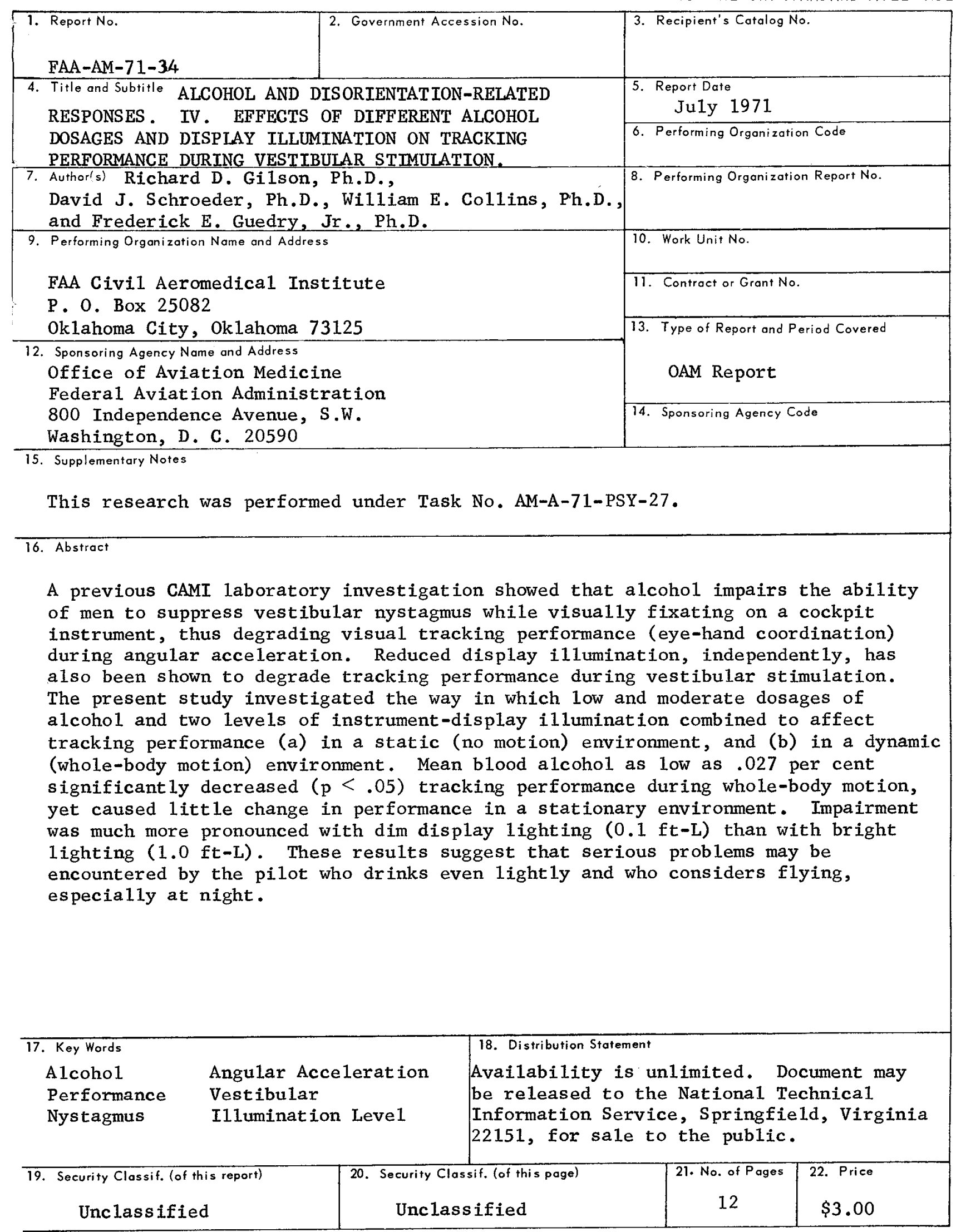

Form DOT F $1700.7(8.69)$ 


\section{ALCOHOL AND DISORIENTATION-RELATED RESPONSES. IV. EFFECTS OF DIFFERENT ALCOHOL DOSAGES AND DISPLAY ILLUMINATION ON TRACKING PERFORMANCE DURING VESTIBULAR STIMULATION.}

\section{Introduction}

Recently, effects of laboratory vestibular stimulation on the visibility of a cockpit instrument have been examined. ${ }^{123}$ These effects have been of interest because eye movements induced by whole-body angular acceleration normally help to stabilize the position of the eye in relation to stationary objects, but they are inappropriate for viewing objects which are moving with the observer. In flight situations, the result can be blurring of vision in the cockpit and impairment of performance.

A pilot can usually suppress these eye movements by fixation on an instrument. Evidence has been presented, however, that this suppressive ability is impaired after alcohol consumption and that compensatory tracking performance is affected. ${ }^{2}$ Thus, although visibility of cockpit instruments and tracking performance may not be measurably degraded by some amounts of alcohol in static environments (absence of vestibular stimulation), they may be seriously impaired during dynamic flight environments.

This problem may be even more severe at night since reduced display illumination recommended for night flying has been shown to increase the

This study was conducted at the FAA's Civil Aeromedical Institute and was co-sponsored by the FAA, the Army (U.S. Army Medical Research and Development Command) and the Navy (USN Aerospace Medical Research Laboratory, Pensacola). Lt. Gilson is a Research Psychologist and Dr. Guedry is Head, Psychophysiology Division at USNAMRL; Dr. Schroeder is a Research Psychologist and Dr. Collins is Chief of the Psychology Laboratory at CAMI. The expert assistance of Carl Moore in obtaining the blood samples, and of Elizabeth Gilson, Carlyn Manley, Cynthia Cochran, and Blair Fennell in the collection and scoring of the data are gratefully acknowledged. Gas chromatographic analyses of the blood samples were performed under contract by Dr. Kurt Dubowski, University of Oklahoma Medical Center. blurring and performance decrements that result from vestibular nystagmus. ${ }^{3}$ Moreover, there is the possibility that even relatively low dosages of alcohol are effective in producing these undesired consequences in dynamic environments.

The present investigation was designed to study the way in which these two conditions, alcohol and low instrument illumination, combine to affect performance during vestibular stimulation.

\section{Method}

A. Subjects. Twenty-four male college students ranging in age from 21 to 30 years served as subjects. Each was a paid volunteer and none had had previous laboratory experience involving vestibular stimulation.

B. Apparatus. The rotational device, recording techniques, eye-movement calibration procedures, and the tracking task have been described in detail previously. ${ }^{2}$ The subject was seated upright in a small cockpit-enclosure mounted on a Stille-Werner RS-3 rotator with his horizontal semicircular canals approximately in the plane of rotation. The angular velocity of the device followed a triangular waveform and alternately reached a peak velocity of $120 \mathrm{deg} / \mathrm{sec}$ in the clockwise and counterclockwise directions. A complete cycle required 48 seconds.

Lateral eye movements were recorded during vestibular stimulation by a conventional electrooculographic technique. Mean values of the nystagmic beats and the amount of slow phase eye velocity were measured at two sample 5second intervals for each trial and were chosen to include maximum nystagmus output in a single direction.

A compensatory visual-tracking task provided the measure of visual performance. $\mathbf{A}$ sinusoidal "forcing function" deflected the vertical needle of an aircraft localizer/glide-slope indicator 
TABLE 1.- Means and standard deviations by session for slow phase nystagmus (deg/sec), frequency of nystagmus (beats/sec), and tracking error (arbitrary units).

\begin{tabular}{|c|c|c|c|c|c|c|c|c|c|c|c|}
\hline \multirow{2}{*}{ Measure } & \multirow{2}{*}{ Group } & \multirow{2}{*}{ Cond. } & & \multicolumn{4}{|c|}{$0.1 \mathrm{ft}$. L Sessions } & \multicolumn{4}{|c|}{$1.0 \mathrm{ft} . \mathrm{L}$ Sessions } \\
\hline & & & & Pre & 1-Hour & 2-Hour & 4-Hour & Pre & 1-Hour & 2-Hour & 4-Hour \\
\hline \multirow{2}{*}{$\begin{array}{l}\text { Slow Phase } \\
\text { Nystagmus }\end{array}$} & \multirow{2}{*}{ Cont. } & \multirow[t]{2}{*}{ Dyn. } & Mean & 6.32 & 4.84 & 3.59 & 3.21 & 7.06 & 5.19 & 3.39 & 3.59 \\
\hline & & & SD & 2.87 & 2.06 & 1.68 & 1.11 & 3.24 & 2.31 & 1.38 & 2.07 \\
\hline \multirow{2}{*}{$\begin{array}{l}\text { Nystagmus } \\
\text { Frequency }\end{array}$} & \multirow[t]{2}{*}{ Cont. } & \multirow[t]{2}{*}{ Dyn. } & Mean & 2.38 & 2.14 & 1.71 & 1.52 & 2.52 & 2.15 & 1.59 & 1.70 \\
\hline & & & $\mathrm{SD}$ & 0.56 & 0.80 & 0.63 & 0.25 & 0.56 & 0.54 & 0.62 & 0.57 \\
\hline \multirow{2}{*}{$\begin{array}{l}\text { Slow Phase } \\
\text { Nystagmus }\end{array}$} & Low & \multirow[t]{2}{*}{ Dyn. } & Mean & 7.00 & 8.12 & 6.81 & 3.65 & 5.36 & 7.54 & 4.66 & 3.18 \\
\hline & Alco. & & SD & 4.92 & 4.87 & 4.55 & 2.04 & 3.06 & 3.73 & 3.07 & 1.66 \\
\hline \multirow{2}{*}{$\begin{array}{l}\text { Nystagmus } \\
\text { Frequency }\end{array}$} & Low & \multirow[t]{2}{*}{ Dyn. } & Mean & 2.01 & 2.60 & 2.09 & 1.35 & 1.9 & 2.56 & 1.64 & 1.28 \\
\hline & Alco. & & $\mathrm{SD}$ & 1.07 & 1.20 & 0.96 & 0.73 & 0.99 & 0.99 & 0.99 & 0.71 \\
\hline \multirow{2}{*}{$\begin{array}{l}\text { Slow Phase } \\
\text { Nystagmus }\end{array}$} & Mod. & \multirow[t]{2}{*}{ Dyn } & Mean & 5.52 & 15.35 & 11.09 & 6.46 & 5.85 & 12.46 & 10.25 & 6.39 \\
\hline & Alco. & & SD & 1.69 & 8.30 & 7.68 & 3.41 & 2.52 & 6.20 & 6.12 & 2.75 \\
\hline \multirow{2}{*}{$\begin{array}{l}\text { Nystagmus } \\
\text { Frequency }\end{array}$} & Mod. & \multirow[t]{2}{*}{ Dyn. } & Mean & 2.27 & 3.10 & 3.00 & 2.30 & 2.25 & 3.16 & 3.00 & 2.44 \\
\hline & Alco. & & SD & 0.55 & 0.87 & 0.84 & 0.74 & 0.68 & 0.93 & 0.78 & 0.73 \\
\hline \multirow{4}{*}{$\begin{array}{l}\text { Tracking } \\
\text { Error }\end{array}$} & \multirow[t]{2}{*}{ Cont. } & \multirow{2}{*}{ Stat. } & Mean & 4.57 & 4.38 & 4.22 & 3.77 & 4.23 & 4.01 & 3.59 & 3.76 \\
\hline & & & SD & 1.24 & 1.07 & 0.51 & 0.81 & 1.05 & 1.17 & 0.58 & 0.84 \\
\hline & \multirow[t]{2}{*}{ Cont. } & \multirow[t]{2}{*}{ Dyn. } & Mean & 6.90 & 5.66 & 4.91 & 5. 18 & 5.93 & 4.86 & 4.62 & 4.63 \\
\hline & & & $\mathrm{SD}$ & 1.68 & 1.57 & 1.52 & 1.41 & 1.83 & 1.31 & 1.03 & 1.19 \\
\hline \multirow{4}{*}{$\begin{array}{l}\text { Tracking } \\
\text { Error }\end{array}$} & Low & \multirow[t]{2}{*}{ Stat. } & Mean & 5.18 & 4.27 & 3.84 & 3.17 & 4.75 & 4.30 & 3.56 & 3.01 \\
\hline & Alco. & & SD & 1.98 & 1.83 & 1.28 & 1.74 & 1.94 & 1.77 & 1.45 & 0.97 \\
\hline & Low & \multirow[t]{2}{*}{ Dyn. } & Mean & 7.16 & 7.22 & 6.19 & 5.00 & 5.36 & 5.52 & 4.72 & 3.88 \\
\hline & Alco. & & $\mathrm{SD}$ & 2.13 & 2.99 & 3.58 & 2.91 & 1.53 & 1.41 & 1.79 & 1.51 \\
\hline \multirow{4}{*}{$\begin{array}{l}\text { Tracking } \\
\text { Error }\end{array}$} & Mod. & \multirow[t]{2}{*}{ Stat. } & Mean & 5.39 & 5.02 & 4.60 & 3.81 & 5.06 & 4.93 & 4.48 & 3.67 \\
\hline & Alco. & & SD & 1.60 & 1.04 & 0.70 & 0.65 & 1.73 & 1.55 & 1.02 & 0.58 \\
\hline & Mod. & Dyn. & Mean & 6.66 & 10.99 & 8.27 & 6.23 & 6.12 & 7.89 & 6.01 & 4.85 \\
\hline & Alco. & & $\mathrm{SD}$ & 1.27 & 2.66 & 2.24 & 1.27 & 1.32 & 2.17 & 1.53 & 0.99 \\
\hline
\end{tabular}

while the subject attempted to maintain the needle in the null position by manipulation of a control stick. Deviations of the needle were considered as errors and these were integrated over consecutive 1-second intervals. The values were then summed and an average value was obtained for each trial.

Light was projected through a tube to localize on the display and to minimize reflection in the otherwise darkened room. Voltage across the $3 \mathrm{vDC}$ light source was adjusted for a luminance of $1.0 \mathrm{ft}-\mathrm{L}$ (in a calibration procedure using a MacBeth illuminometer). A second illumination level of $0.1 \mathrm{ft}-\mathrm{L}$ was also used; this was produced by placing a 1.0 neutral density filter in front of the projected light source. Both levels of illumination are within a range recommended for aircraft instruments. ${ }^{4}$

C. Procedure. Prior to being tested, each subject was given five minutes of tracking practice with the rotational device stationary. He then underwent an experimental sequence consisting of four tracking sessions: a pre-drinking session and post-drinking sessions at 1, 2, and 4 hours after a 30-minute drinking period had been completed. 
Each session consisted of 2.5 minutes of "static" tracking with the rotational device stationary, and 2.5 minutes of "dynamic" tracking with the device rotating. This was carried out with the two display illumination levels, one trial at 1.0 $\mathrm{ft}-\mathrm{L}$ and one trial at the $0.1 \mathrm{ft}-\mathrm{L}$ level. The order of presentation of these conditions (static or dynamic tracking and a bright or dim display illumination) was counterbalanced across subjects, and at least a 1-minute interval was allowed between tracking periods. Before each testing session, a venous blood sample was drawn from those subjects receiving alcohol for analysis of blood alcohol by gas chromatography; only one blood sample was taken from each control subject. Eye-movement calibrations were obtained for each session.

Three groups were used, each composed of eight subjects. Those in two groups received a mixture of 100-proof Smirnoff vodka and orange juice. Subjects in the "low alcohol" group received one $\mathrm{ml}$ of vodka per kilogram of body weight and those in the "moderate alcohol" group received two $\mathrm{ml}$ of vodka per kilogram of body weight. Subjects in the control group were given orange juice without vodka but with a few drops of rum extract added to impart an alcoholic taste. Subjects were separated by groups and were not informed concerning the amounts of alcohol they had received.

\section{Results}

The mean blood alcohol level for the moderate alcohol group was .077 per cent, slightly more than double the .027 per cent level for the low alcohol group at the one-hour testing session. After two hours, these blood alcohol levels were reduced to .076 per cent and .018 per cent, respectively; after four hours they were further reduced to .041 per cent and .000 per cent, respectively (see Appendix A).

Means and standard deviations for the slow phase and frequency measures of nystagmus during dynamic trials and for tracking error during both static and dynamic trials are presented in Table 1 for both conditions of display illumination. Figure 1 represents the measured samples of nystagmus as mean values of slow phase velocity in $\mathrm{deg} / \mathrm{sec}$ and frequency in beats/ sec plotted for the two levels of illumination and separated by group. Both measures show essen- tially the same results: that nystagmus in light is disinhibited after consumption of alcohol. Subjects in both alcohol groups show a sizeable first-hour increase in the nystagmus measures from the pre-drinking level, whereas those in the control group show a decrease in nystagmus with repeated trials. The reduction of one log unit in display illumination was relatively ineffective in changing nystagmus, although the $0.1 \mathrm{ft}-\mathrm{L}$ level is associated with somewhat greater nystagmus. Samples of tracings appear in Figure 2. (Nystagmus and performance scores for individual subjects appear in Appendix B-G.)

The tracking results are shown in Figure 3 as the percentage increase or decrease in tracking error for the three post-drinking tests with respect to the pre-drinking error level. These are plotted for the three groups and the four testing conditions: tracking with or without vestibular stimulation (dynamic or static) and with a display illumination of either 0.1 or $1.0 \mathrm{ft}-\mathrm{L}$ (dim or bright). Results of statistical comparisons are in Tables 2 and 3.

Tracking errors increased over the pre-drinking level only for the alcohol groups during dynamic tracking. Although this effect is more striking for those in the moderate alcohol group, it is apparent that those in the low alcohol group also exhibited the effect. (The difference between the low alcohol and the control group is significant at the .05 level for the first postdrinking test. See Table 3.)

Also apparent is that the dim display illumination greatly increased the error rate during dynamic tracking. For the decrease of one $\log$ unit in luminance, the error rate increase was approximately doubled (see Figure 3).

During static tracking, however, the alcohol groups did no worse than the controls; during most of the static testing they decreased their errors somewhat more quickly. This again was more apparent under dim illumination than bright.

\section{Discussion}

The results show clearly, despite what appears to be for the control group a persistent practice effect, that alcohol ingestion significantly decreased performance during vestibular stimulation yet caused little change in static tracking performance. 


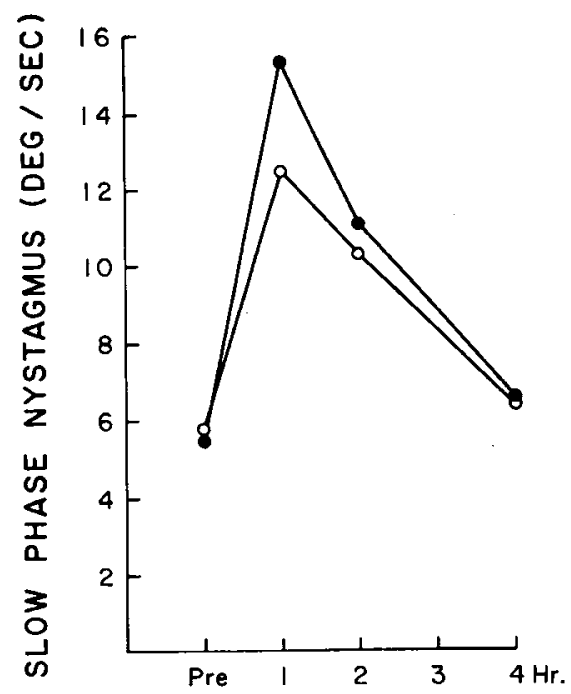

MODERATE ALCOHOL

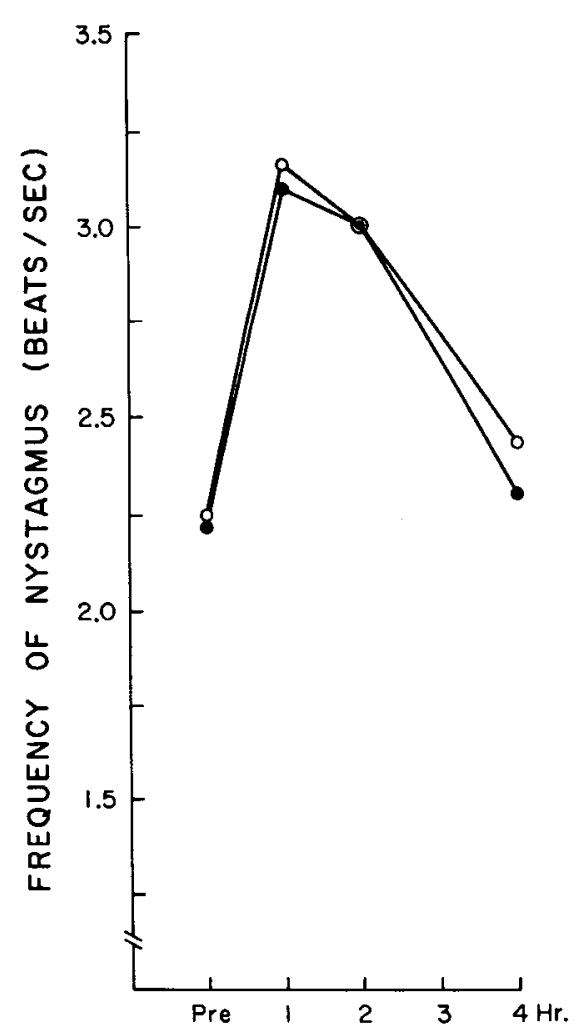

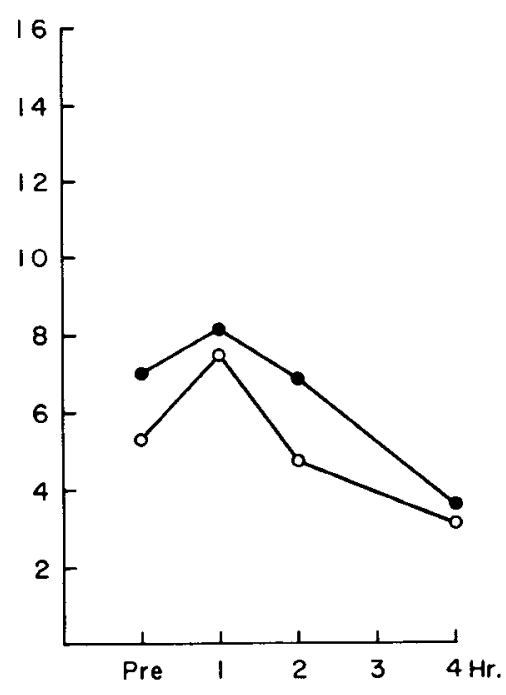

LOW ALCOHOL

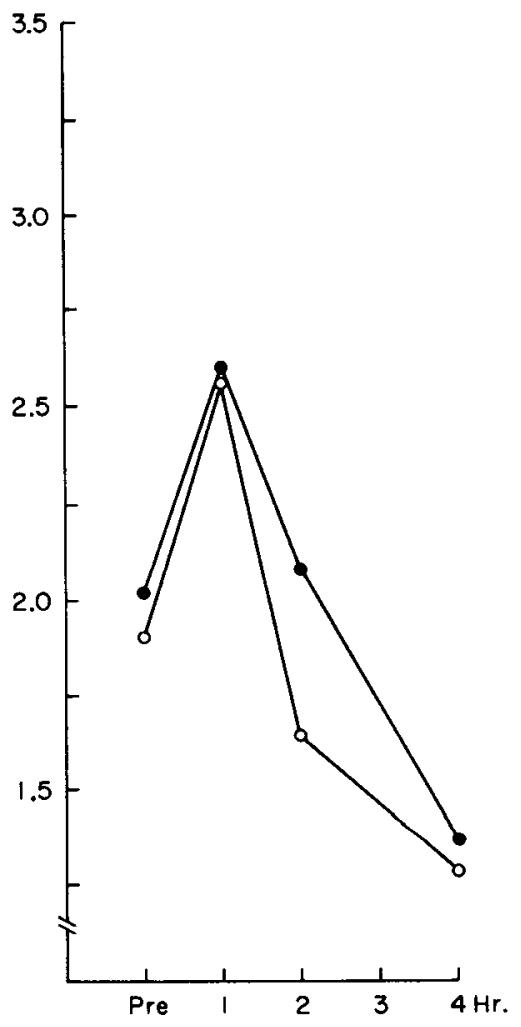

TIME AFTER DRINKING
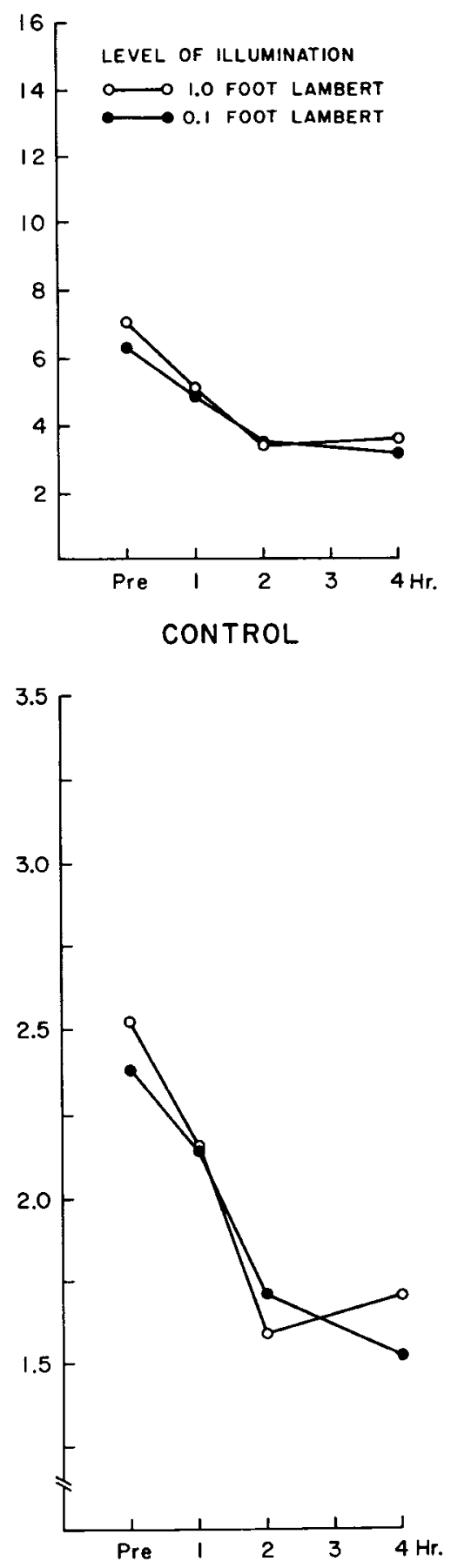

Figure 1. Frequency and slow phase velocity of nystagmus during angular acceleration for the control and alcohol groups. 

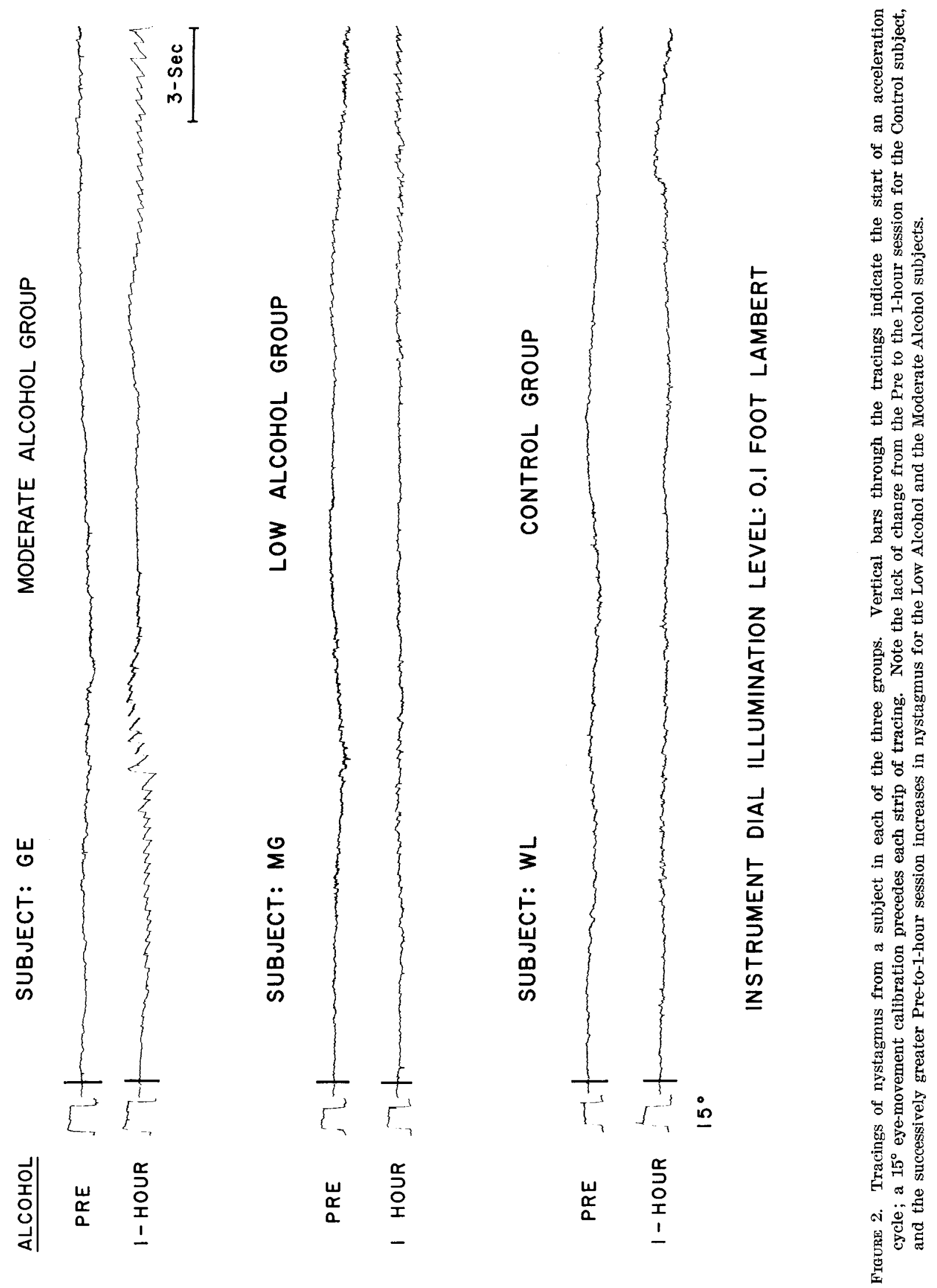
TABL 2-Results of t tests between pre-alcohol and each post-alcohol measure of the slow phase displacement and the frequency of nystagmus resulting from angular accelerations and of tracking error under static and dynamic conditions

Nystagmus Comparisons: Pre vs.

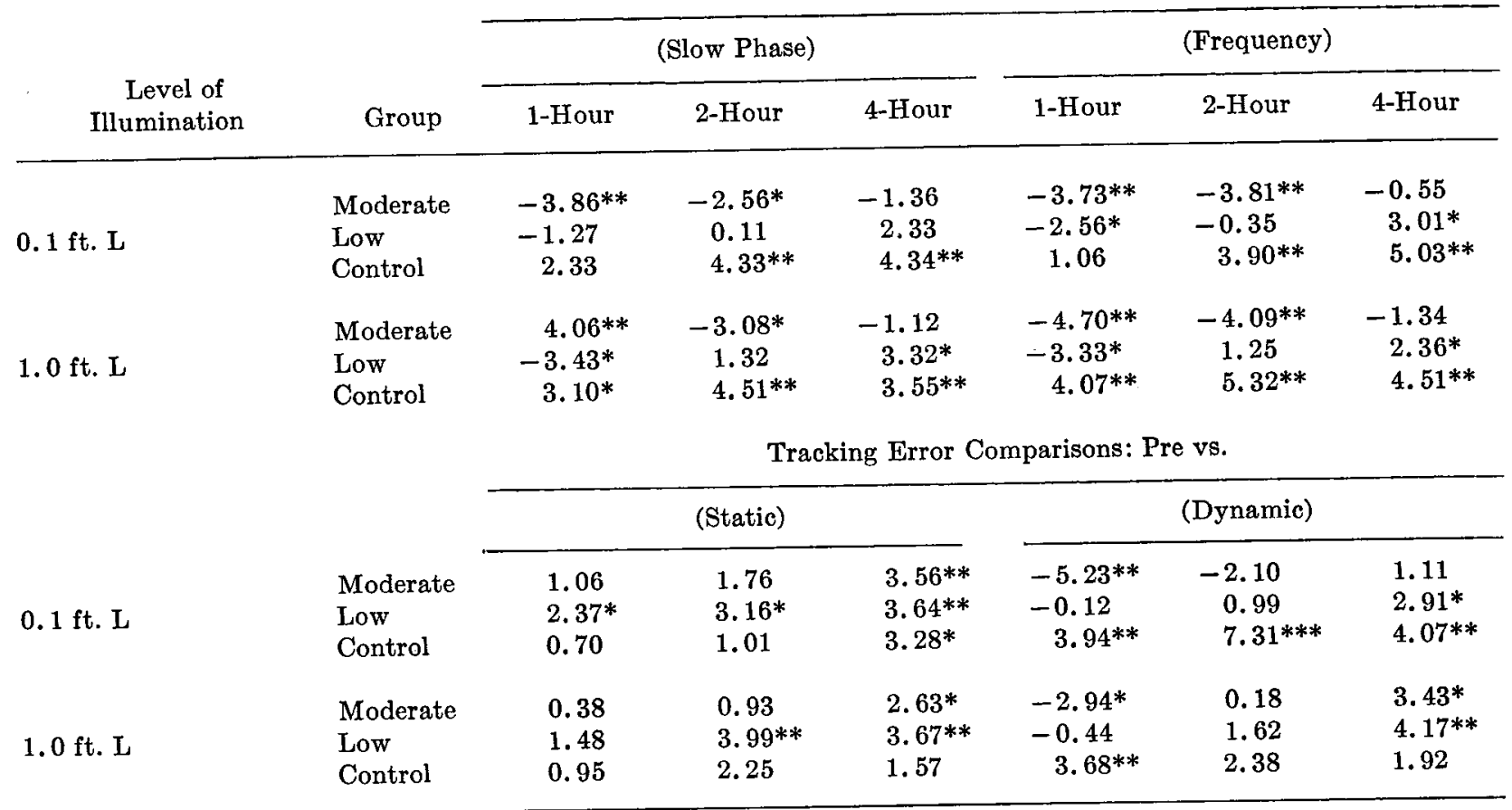

$* \mathrm{p}<.05 \quad * * \mathrm{p}<.01 \quad * * * \mathrm{p}<.001$

TABLE 3.- Results of $t$ tests comparing Control, Moderate Alcohol, and Low Alcohol subjects on measures of nystagmus and tracking error. Comparisons were made between difference scores for each session (i.e., the difference in scores of each post-ingestion session from those of the pre-ingestion session).

\begin{tabular}{|c|c|c|c|c|c|c|c|}
\hline \multirow{2}{*}{$\begin{array}{l}\text { Level of } \\
\text { Illumination }\end{array}$} & \multirow[b]{2}{*}{ Comparison } & \multicolumn{3}{|c|}{ Slow Phase } & \multicolumn{3}{|c|}{ Frequency } \\
\hline & & 1-Hour & 2-Hour & 4-Hour & 1-Hour & 2-Hour & 4-Hour \\
\hline $0.1 \mathrm{ft} . \mathrm{L}$ & $\begin{array}{l}C \text { vs } L \\
C \text { vs } M \\
M \text { vs } L\end{array}$ & $\begin{array}{l}-2.39^{*} \\
-4.31^{* * *} \\
3.23^{* *}\end{array}$ & $\begin{array}{l}-1.40 \\
-3.67 * * \\
2.08\end{array}$ & $\begin{array}{l}0.15 \\
-4.07^{* * *} \\
2.68^{*}\end{array}$ & $\begin{array}{l}-2.57^{*} \\
-3.43^{* *} \\
0.88\end{array}$ & $\begin{array}{l}-2.68^{*} \\
-5.42^{* * *} \\
2.35^{*}\end{array}$ & $\begin{array}{l}-0.37 \\
-4.25 * * * \\
2.84 *\end{array}$ \\
\hline $1.0 \mathrm{ft} . \mathrm{L}$ & $\begin{array}{l}C \text { vs } L \\
C \text { vs } M \\
M \text { vs } L\end{array}$ & $\begin{array}{l}-4.62 * * * \\
-4.88 * * * \\
2.54 *\end{array}$ & $\begin{array}{c}-3.06^{* *} \\
-4.91^{* * *} \\
3.35^{* *}\end{array}$ & $\begin{array}{l}-1.09 \\
-3.68^{* *} \\
3.34^{* *}\end{array}$ & $\begin{array}{l}-4.73^{* * *} \\
-5.99^{* * *} \\
0.90\end{array}$ & $\begin{array}{c}2.46^{*} \\
-6.64^{* * *} \\
3.62^{* *}\end{array}$ & $\begin{array}{l}-0.62 \\
-4.40^{* * *} \\
2.71^{*}\end{array}$ \\
\hline & & \multicolumn{3}{|c|}{ Static Tracking Error } & \multicolumn{3}{|c|}{ Dynamic Tracking Error } \\
\hline $0.1 \mathrm{ft.} \mathrm{L}$ & $\begin{array}{l}C \text { vs } L \\
C \text { vs } M \\
M \text { vs } L\end{array}$ & $\begin{array}{l}1.54 \\
0.42 \\
1.03\end{array}$ & $\begin{array}{l}1.83 \\
0.78 \\
0.90\end{array}$ & $\begin{array}{l}2.02 \\
1.55 \\
0.61\end{array}$ & $\begin{array}{r}-2.31^{*} \\
-6.29 * * * \\
4.51 * * *\end{array}$ & $\begin{array}{l}-1.02 \\
-4.42^{* * *} \\
2.08\end{array}$ & $\begin{aligned} & 0.50 \\
-2.25^{*} & \\
& 2.06\end{aligned}$ \\
\hline $1.0 \mathrm{ft} . \mathrm{L}$ & $\begin{array}{l}C \text { vs } L \\
C \text { vs } M \\
M \text { vs } L\end{array}$ & $\begin{array}{r}0.57 \\
-0.19 \\
0.66\end{array}$ & $\begin{array}{c}1.32 \\
-0.08 \\
2.26^{*}\end{array}$ & $\begin{array}{l}2.26^{*} \\
1.51 \\
0.48\end{array}$ & $\begin{array}{l}-2.67^{*} \\
-4.27^{* * *} \\
2.31^{*}\end{array}$ & $\begin{array}{r}-0.99 \\
-1.40 \\
0.69\end{array}$ & $\begin{array}{r}0.23 \\
-0.03 \\
0.38\end{array}$ \\
\hline
\end{tabular}

$$
* \mathrm{p}<.05 \quad * * \mathrm{p}<.01 \quad * * * \mathrm{p}<.001
$$



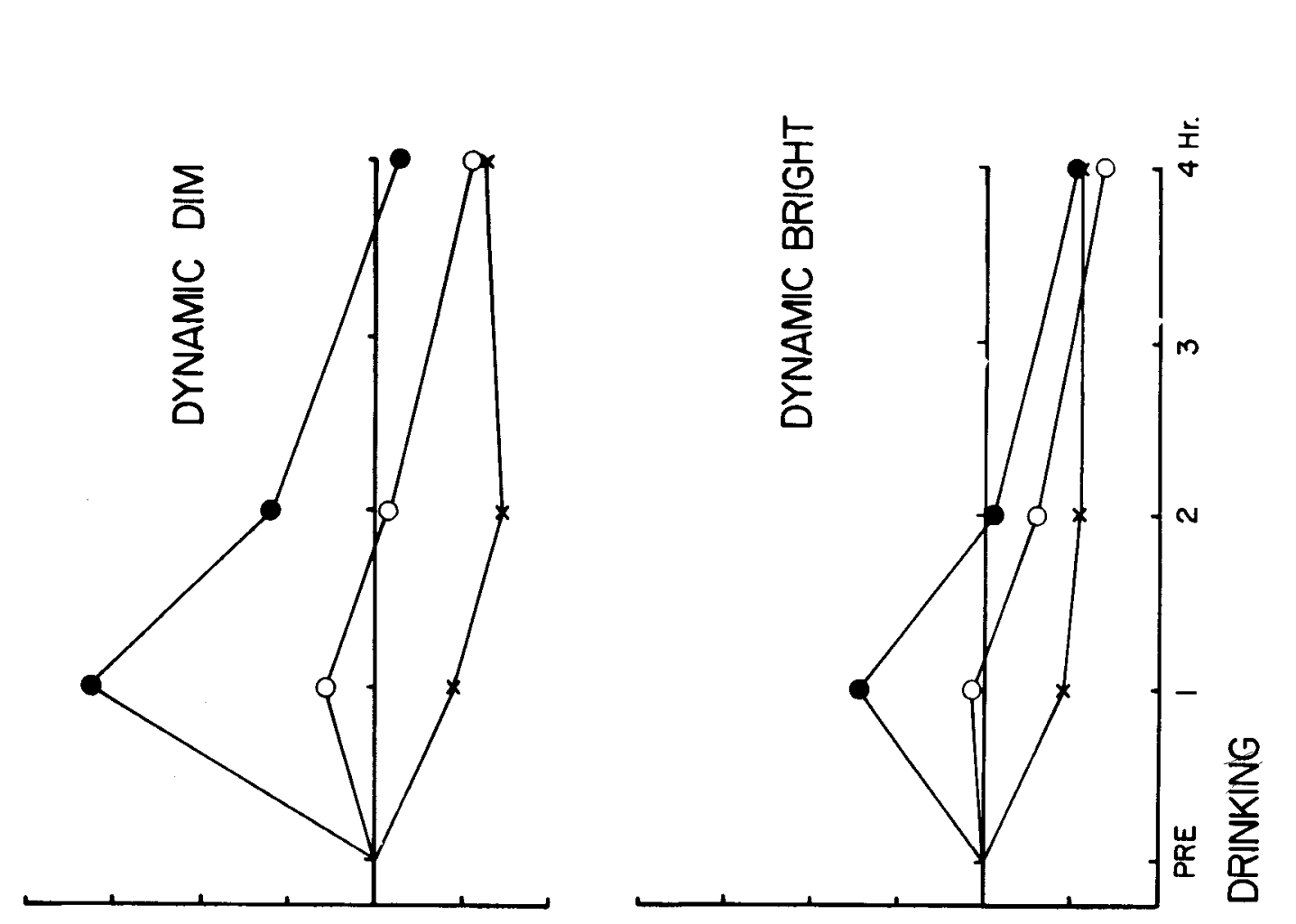

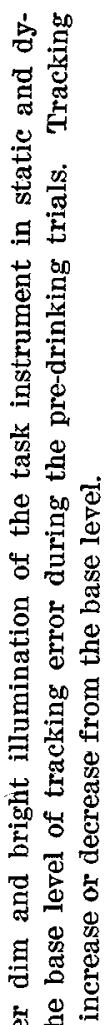

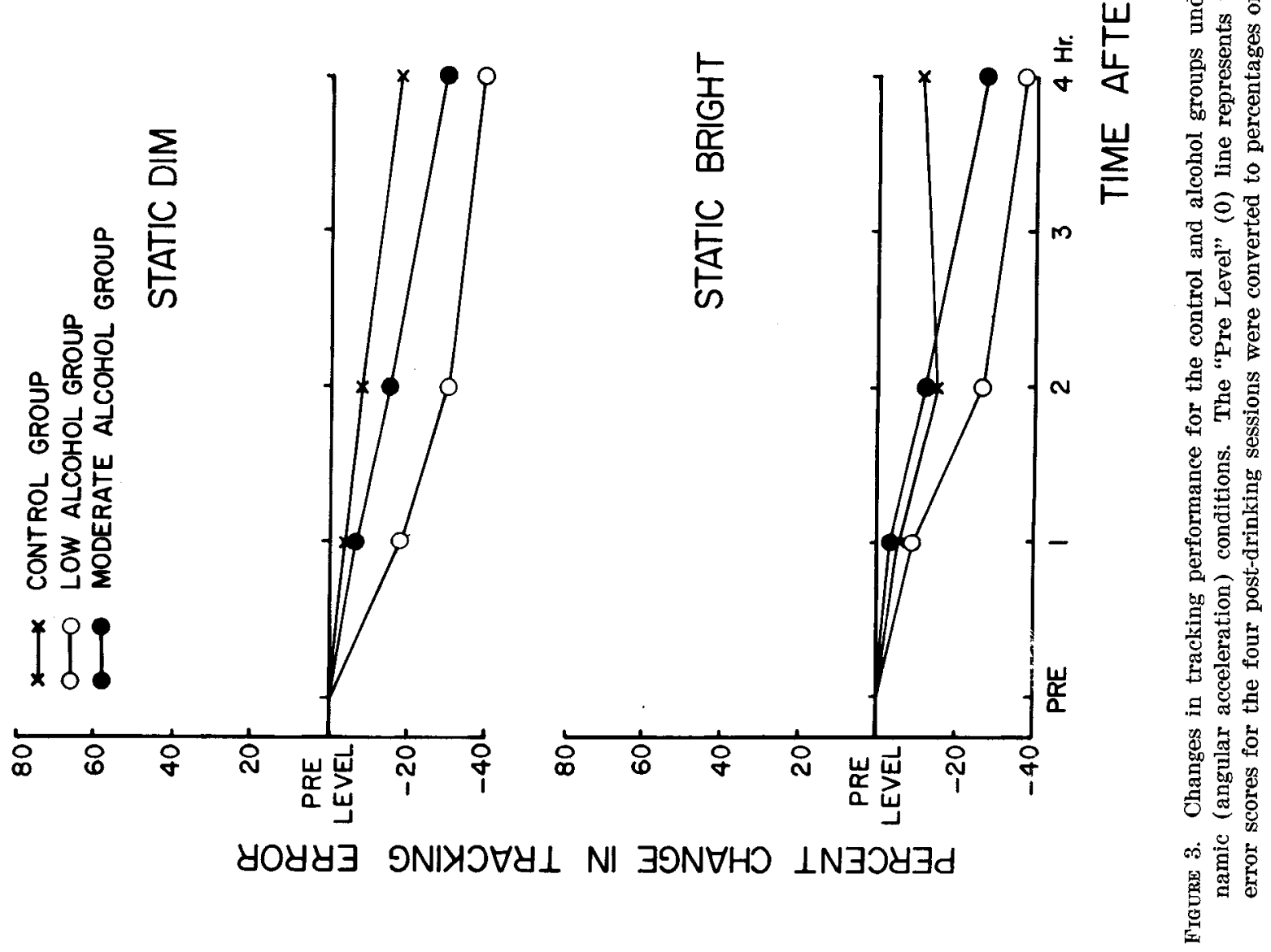


A. Static Tracking. During static tracking; vestibular nystagmus was not present, and therefore there was no visual blurring or performance impairment from this source. The slightly faster improvement in static tracking performance across sessions by those given the low alcohol dose over the control group may have occurred because of awareness on the part of these subjects that they had actually received alcohol and a concomitant increase in their motivation to "prove they could do it." However, the only point at which there was any significant difference between the control and low alcohol groups in static tracking was during the 4-hour postdrinking session when there were no longer measurable quantities of alcohol present in the blood samples of the low alcohol subjects; as such, the static tracking differences may more closely reflect differences in eye-hand coordination abilities among the groups.

B. Dynamic Tracking. These results confirm those reported in a previous study, ${ }^{2}$ which showed that the vestibular nystagmus evoked during dynamic tracking was not suppressed as well by subjects under the influence of moderate alcohol dosages. Thus, blurring of vision and the impairment of performance ensued. The present study indicates that these same effects are significant for average blood alcohol levels as low as .027 per cent. It should be noted that these latter alcohol levels were achieved with alcohol dosages equivalent to less than two social drinks for the average-sized man.

C. Display Illumination. The effects of vestibular stimulation on tracking were much more pronounced during the dim display illumination. Increased blurring and performance degradation with reduced illumination during dynamic tracking has previously been reported ${ }^{3}$ and the absence of a commensurate change in nystagmus was cited as evidence of a visual phenomenon. This phenomenon was magnified in the present study by the unsuppressed nystagmus due to alcohol. The combination of the dim illumination, vestibular stimulation, and the influence of alcohol produced the poorest tracking performance, whereas the control group, with greatly suppressed nystagmus, was not affected significantly by the illumination change at these relatively low angular velocities.

D. Implications. The dramatic impairment in tracking performance only in the dynamic environment shows the insidious nature of this effect. A pilot who drinks lightly may be able to convince himself on the ground that his abilities are unimpaired and thus may feel safe to enter the cockpit. Results of this study suggest, however, that he is entering a potentially dangerous situation. If, while flying, particularly at night with dim display illumination, that pilot encounters vestibular stimulation as a result of maneuvers, turbulence, or some inner ear dysfunction, he may experience blurring of vision. The visual control of his eye movements will have been reduced by the alcohol and vestibular control is free to take over driving the eyes relative to the instruments. This increases the likelihood that he will misread the instruments and react incorrectly, causing more severe maneuvering and what may be the beginning of an irreversible, vicious circle.

\section{REFERENCES}

1. Benson, A. J., and F. E. Guedry: Comparison of tracking task performance and nystagmus during sinusoidal oscillation in yaw and pitch. NAMRL-1123 and USAARI No. 71-12. Pensacola, Fla.: Naval Aerospace Medical Research Laboratory, 1970.

2. Collins, W. E., R. D. Gilson, D. J. Schroeder, and F. E. Guedry: Alcohol and disorientation-related responses. III. Effects of alcohol ingestion on tracking performance during angular acceleration. FAA
Office of Aviation Medicine Report No. FAA-AM$71-20,1971$.

3. Gilson, R. D., F. E. Guedry, and A. J. Benson: Influence of vestibular stimulation and display luminance on the performance of a compensatory tracking task, AEROSPACE MEDICINE, $41: 1231,1970$.

4. Morgan, C. T., J. S. Cook, A. Chapanis, and M. W. Lund: Human Engineering, Guide to Equipment Design, New York, McGraw-Hill, 1963. 
APPENDIX A-Blood alcohol levels in percent determined by gas chromatography for Alcohol and Control subjects.

\begin{tabular}{|c|c|c|c|c|c|c|c|c|c|c|c|c|}
\hline \multicolumn{3}{|c|}{ Control Group } & \multicolumn{5}{|c|}{ Low Alcohol } & \multicolumn{5}{|c|}{ Moderate Alcohol } \\
\hline & \multirow[b]{2}{*}{ Subj. } & \multirow[b]{2}{*}{ Pre } & \multirow[b]{2}{*}{ Subj. } & \multicolumn{4}{|c|}{ Session } & \multirow[b]{2}{*}{ Subj. } & \multicolumn{4}{|c|}{ Session } \\
\hline & & & & Pre & $1-\mathrm{Hr}$. & $2-\mathrm{Hr}$ & $4-\mathrm{Hr}$. & & Pre & $1-\mathrm{Hr}$. & 2-Hr. & 4-Hr. \\
\hline JJ & & 0 & $\mathrm{MG}$ & 0 & .032 & .024 & 0 & $\mathrm{BT}$ & 0 & .068 & .068 & .037 \\
\hline $\mathrm{TL}$ & & 0 & $\mathrm{BB}$ & 0 & .028 & .014 & 0 & $\mathrm{GE}$ & 0 & .078 & .086 & .068 \\
\hline JB1 & & 0 & RK & 0 & .012 & .007 & 0 & FS & 0 & .081 & .082 & .046 \\
\hline $\mathrm{CH}$ & & 0 & $\mathrm{LS}$ & 0 & .031 & .023 & 0 & $\mathrm{VH}$ & 0 & .084 & .067 & .036 \\
\hline PS & & 0 & $\mathrm{FE}$ & 0 & .011 & .012 & 0 & LJJ & 0 & .109 & .102 & .041 \\
\hline DM & & 0 & $\mathrm{RF}$ & 0 & .031 & .016 & 0 & BS & 0 & .071 & .074 & .032 \\
\hline WL & & $\mathbf{0}$ & $\mathrm{CD}$ & 0 & .043 & .028 & 0 & $\mathrm{FG}$ & 0 & .053 & .056 & .029 \\
\hline $\mathrm{JBt}$ & & 0 & $\mathrm{PD}$ & 0 & .028 & .017 & 0 & $\mathrm{JM}$ & 0 & .071 & .071 & .035 \\
\hline Mean & & $\overline{0}$ & Mean & $\overline{0}$ &.$\overline{.027}$ & $\overline{.018}$ & $\overline{0}$ & Mean & $\overline{0}$ & $\overline{.077}$ & $\overline{.076}$ & $\overrightarrow{.041}$ \\
\hline $\mathrm{SD}$ & & 0 & SD & 0 & .011 & .007 & 0 & $\mathrm{SD}$ & 0 & .016 & .014 & .012 \\
\hline
\end{tabular}

APpendix B.-Control Group: Nystagmus measures from the angular accelerations based on two 5-sec samples from each session for each subject.

\begin{tabular}{|c|c|c|c|c|c|c|c|c|c|}
\hline \multirow{2}{*}{$\begin{array}{l}\text { Level of } \\
\text { Illumination }\end{array}$} & \multirow[b]{2}{*}{ Subject } & \multicolumn{4}{|c|}{ Slow Phase Nystagmus (deg/sec) } & \multicolumn{4}{|c|}{ Frequency (beats/sec) } \\
\hline & & Pre & 1-Hour & 2-Hour & 4-Hour & Pre & 1-Hour & 2-Hour & 4-Hour \\
\hline \multirow{8}{*}{$0.1 \mathrm{ft} . \mathrm{L}$} & JJ & 2.9 & 3.0 & 2.5 & 2.0 & 1.9 & 1.8 & 1.4 & 1.3 \\
\hline & $\mathrm{TL}$ & 6.6 & 4.7 & 3.5 & 3.6 & 2.3 & 2.3 & 1.8 & 1.8 \\
\hline & JB1 & 6.7 & 8.1 & 4.6 & 3.4 & 2.6 & 3.1 & 2.7 & 1.6 \\
\hline & $\mathrm{CH}$ & 7.7 & 4.5 & 4.2 & 4.4 & 2.9 & 1.3 & 1.5 & 1.7 \\
\hline & PS & 10.7 & 7.0 & 4.2 & 3.5 & 3.2 & 3.4 & 2.0 & 1.4 \\
\hline & $D M$ & 4.7 & 3.1 & 2.5 & 2.6 & 2.3 & 1.7 & 1.8 & 1.5 \\
\hline & WL & 8.9 & 6.0 & 6.4 & 4.7 & 2.4 & 2.3 & 2.0 & 1.8 \\
\hline & JBt & 2.4 & 2.3 & 0.8 & 1.5 & 1.4 & 1.2 & 0.5 & 1.1 \\
\hline \multirow{12}{*}{$1.0 \mathrm{ft} . \mathrm{L}$} & Mean & 6.32 & 4.84 & 3.59 & 3.21 & 2.38 & 2.14 & 1.71 & 1.52 \\
\hline & $\mathrm{SD}$ & 2.87 & 2.06 & 1.68 & 1.11 & 0.56 & 0.80 & 0.63 & 0.25 \\
\hline & $\mathbf{J J}$ & 4.7 & 2.8 & 2.9 & 1.7 & 2.0 & 1.5 & 1.4 & 1.0 \\
\hline & $\mathrm{TL}$ & 5.3 & 5.1 & 3.2 & 2.6 & 2.6 & 1.9 & 2.1 & 1.9 \\
\hline & JB1 & 8.5 & 6.0 & 4.1 & 3.6 & 3.0 & 2.8 & 1.9 & 2.1 \\
\hline & $\mathrm{CH}$ & 8.6 & 8.5 & 3.1 & 3.8 & 2.0 & 2.1 & 1.0 & 1.3 \\
\hline & PS & 13.0 & 7.9 & 5.1 & 4.0 & 3.6 & 3.0 & 2.1 & 1.8 \\
\hline & $\mathrm{DM}$ & 3.8 & 3.3 & 3.1 & 3.5 & 2.4 & 2.2 & 2.3 & 2.2 \\
\hline & WL & 8.9 & 5.7 & 4.9 & 8.1 & 2.6 & 2.2 & 1.4 & 2.4 \\
\hline & $\mathrm{JBt}$ & 3.7 & 2.2 & 0.7 & 1.4 & 2.0 & 1.5 & 0.5 & 0.9 \\
\hline & Mean & 7.06 & 5.19 & 3.39 & 3.59 & 2.52 & 2.15 & 1.59 & 1.70 \\
\hline & $\mathrm{SD}$ & 3.24 & 2.31 & 1.38 & 2.07 & 0.56 & 0.54 & 0.62 & 0.57 \\
\hline
\end{tabular}


ApPendix C.-Low Alcohol Group: Nystagmus measures from the angular accelerations based on two 5-sec samples from each session for each subject.

\begin{tabular}{|c|c|c|c|c|c|c|c|c|c|}
\hline \multirow{2}{*}{$\begin{array}{l}\text { Level of } \\
\text { Illumination }\end{array}$} & \multirow[b]{2}{*}{ Subject } & \multicolumn{4}{|c|}{ Slow Phase Nystagmus (deg/sec) } & \multicolumn{4}{|c|}{ Frequency (beats/sec) } \\
\hline & & Pre & 1-Hour & 2-Hour & 4-Hour & Pre & 1-Hour & 2-Hour & 4-Hour \\
\hline \multirow{8}{*}{$0.1 \mathrm{ft} . \mathrm{L}$} & $\mathrm{MG}$ & 15.3 & 18.7 & 14.6 & 7.7 & 3.9 & 4.7 & 3.8 & 2.4 \\
\hline & $\mathrm{BB}$ & 13.8 & 11.1 & 5.6 & 2.6 & 2.8 & 3.2 & 1.8 & 1.1 \\
\hline & RK & 3.8 & 4.1 & 13.1 & 3.2 & 0.9 & 1.1 & 1.9 & 0.7 \\
\hline & LS & 6.6 & 5.8 & 3.9 & 2.4 & 1.7 & 1.8 & 1.7 & 0.9 \\
\hline & FE & 3.0 & 4.0 & 2.9 & 3.4 & 1.2 & 1.3 & 0.8 & 1.2 \\
\hline & $\mathrm{RF}$ & 5.6 & 8.5 & 6.4 & 4.7 & 2.5 & 3.4 & 3.0 & 2.1 \\
\hline & $\mathrm{CD}$ & 2.0 & 7.0 & 2.7 & 0.8 & 0.8 & 2.8 & 1.3 & 0.4 \\
\hline & PD & 5.9 & 5.8 & 5.3 & 4.4 & 2.3 & 2.5 & 2.4 & 2.0 \\
\hline \multirow{12}{*}{$1.0 \mathrm{ft} . \mathrm{L}$} & Mean & 7.00 & 8.12 & 6.81 & 3.65 & 2.01 & 2.60 & 2.09 & 1.35 \\
\hline & $\mathrm{SD}$ & 4.92 & 4.87 & 4.55 & 2.04 & 1.07 & 1.20 & 0.96 & 0.73 \\
\hline & $\mathrm{MG}$ & 11.1 & 16.3 & 11.7 & 6.6 & 3.3 & 4.5 & 3.5 & 2.2 \\
\hline & $\mathrm{BB}$ & 6.7 & 6.8 & 5.8 & 2.8 & 1.9 & 1.9 & 1.7 & 0.8 \\
\hline & RK & 4.2 & 7.0 & 2.7 & 3.0 & 1.3 & 2.3 & 0.6 & 0.9 \\
\hline & $\mathrm{LS}$ & 6.3 & 5.9 & 3.0 & 2.8 & 2.8 & 2.4 & 1.3 & 1.0 \\
\hline & $\mathrm{FE}$ & 2.2 & 5.3 & 3.0 & 0.6 & 1.0 & 1.8 & 0.9 & 0.3 \\
\hline & $\mathrm{RF}$ & 5.5 & 7.0 & 4.4 & 3.6 & 2.2 & 3.0 & 2.0 & 1.7 \\
\hline & $\mathrm{CD}$ & 1.1 & 4.1 & 2.3 & 2.5 & 0.3 & 1.4 & 0.7 & 1.0 \\
\hline & PD & 5.8 & 7.9 & 4.4 & 3.5 & 2.4 & 3.2 & 2.4 & 2.3 \\
\hline & Mean & 5.36 & 7.54 & 4.66 & 31.8 & 1.9 & 2.56 & 1.64 & 1.28 \\
\hline & $\mathrm{SD}$ & 3.06 & 3.73 & 3.07 & 1.66 & 0.99 & 0.99 & 0.99 & 0.71 \\
\hline
\end{tabular}

APPEN Drx D.-Moderate Alcohol Group: Nystagmus measures from the angular accelerations based on two 5-sec samples from each session for each subject.

\begin{tabular}{|c|c|c|c|c|c|c|c|c|c|}
\hline \multirow{2}{*}{$\begin{array}{l}\text { Level of } \\
\text { Illumination }\end{array}$} & \multirow[b]{2}{*}{ Subject } & \multicolumn{4}{|c|}{ Slow Phase Nystagmus (deg/sec) } & \multicolumn{4}{|c|}{ Frequency (beats/sec) } \\
\hline & & Pre & 1-Hour & 2-Hour & 4-Hour & Pre & 1-Hour & 2-Hour & 4-Hour \\
\hline \multirow{8}{*}{$0.1 \mathrm{ft} . \mathrm{L}$} & $\mathrm{BT}$ & 3.8 & 7.9 & 6.3 & 2.5 & 1.7 & 2.9 & 2.6 & 2.0 \\
\hline & $\mathrm{GE}$ & 4.3 & 19.8 & 8.7 & 6.3 & 2.0 & 2.4 & 2.6 & 2.5 \\
\hline & FS & 7.1 & 18.8 & 19.0 & 8.4 & 2.2 & 3.7 & 4.0 & 2.5 \\
\hline & $\mathrm{VH}$ & 5.0 & 19.3 & 8.3 & 6.4 & 2.7 & 3.7 & 3.4 & 3.0 \\
\hline & LJ & 4.4 & 11.2 & 7.4 & 4.8 & 1.7 & 3.4 & 2.6 & 1.5 \\
\hline & BS & 5.5 & 7.0 & 7.4 & 5.5 & 1.9 & 2.0 & 2.3 & 1.6 \\
\hline & $\mathrm{FG}$ & 5.2 & 8.0 & 4.8 & 4.1 & 2.3 & 2.2 & 2.1 & 1.7 \\
\hline & $\mathrm{JM}$ & 8.9 & 30.8 & 26.8 & 13.7 & 3.3 & 4.5 & 4.4 & 3.6 \\
\hline \multirow{12}{*}{$1.0 \mathrm{ft.} \mathrm{L}$} & Mean & 5.52 & 15.35 & 11.09 & 6.46 & 2.27 & 3.10 & 3.00 & 2.30 \\
\hline & $\mathrm{SD}$ & 1.69 & 8.30 & 7.68 & 3.41 & 0.55 & 0.87 & 0.84 & 0.74 \\
\hline & $\mathrm{BT}$ & 3.7 & 7.0 & 7.9 & 3.4 & 1.5 & 2.4 & 2.7 & 1.8 \\
\hline & $\mathrm{GE}$ & 4.4 & & & & 2.6 & 3.1 & 3.0 & 3.1 \\
\hline & $\mathrm{FS}$ & 7.0 & 14.3 & 13.4 & 7.6 & 2.3 & 4.3 & 3.8 & 2.8 \\
\hline & $\mathrm{VH}$ & 4.6 & 11.4 & 7.4 & 3.6 & 1.8 & 2.8 & 3.0 & 2.4 \\
\hline & $\mathrm{LJ}$ & 5.5 & 7.8 & 5.7 & 6.2 & 2.3 & 3.4 & 3.1 & 2.4 \\
\hline & BS & 4.9 & 11.1 & 8.0 & 6.3 & 1.9 & 2.6 & 2.2 & 2.1 \\
\hline & $\mathrm{FG}$ & 5.1 & 5.9 & 4.7 & 4.5 & 1.9 & 2.0 & 1.9 & 1.3 \\
\hline & JM & 11.6 & 24.2 & 23.7 & 11.8 & 3.7 & 4.7 & 4.3 & 3.6 \\
\hline & Mean & 5.85 & 12.46 & 10.25 & 6.39 & 2.25 & 3.16 & 3.000 & 2.44 \\
\hline & $\mathrm{SD}$ & 2.52 & 6.20 & 6.12 & 2.75 & 0.68 & 0.93 & 0.78 & 0.73 \\
\hline
\end{tabular}


Appendix E.-Control group: Dynamic and Static tracking error in arbitrary units under bright and dim illumination conditions.

\begin{tabular}{|c|c|c|c|c|c|c|c|c|c|}
\hline \multirow{2}{*}{$\begin{array}{l}\text { Level of } \\
\text { Illumination }\end{array}$} & \multirow[b]{2}{*}{ Subject } & \multicolumn{4}{|c|}{ Static } & \multicolumn{4}{|c|}{ Dynamic } \\
\hline & & Pre & 1-Hour & 2-Hour & 4-Hour & Pre & 1-Hour & 2-Hour & 4-Hour \\
\hline \multirow{8}{*}{$0.1 \mathrm{ft} . \mathrm{L}$} & JJ & 4.98 & 4.05 & 3.80 & 3.22 & 6.96 & 4.67 & 3.86 & 4.25 \\
\hline & $\mathrm{TL}$ & 5.35 & 4.64 & 4.09 & 4.65 & 7.16 & 5.68 & 5.76 & 5.13 \\
\hline & JB1 & 6.65 & 5.43 & 4.97 & 4.88 & 8.73 & 6.85 & 6.27 & 7.32 \\
\hline & $\mathrm{CH}$ & 3.92 & 4.82 & 3.99 & 3.59 & 6.90 & 5.92 & 4.46 & 7.01 \\
\hline & PS & 5.42 & 6.12 & 5.05 & 4.39 & 9.28 & 8.87 & 7.70 & 5.62 \\
\hline & $\mathrm{DM}$ & 2.84 & 3.11 & 4.04 & 2.64 & 4.70 & 4.51 & 3.37 & 3.44 \\
\hline & WL & 3.75 & 3.57 & 4.17 & 3.83 & 7.01 & 4.64 & 4.31 & 4.71 \\
\hline & $\mathrm{JBt}$ & 3.64 & 3.29 & 3.66 & 2.98 & 4.50 & 4.18 & 3.54 & 3.92 \\
\hline \multirow{12}{*}{$1.0 \mathrm{ft.} \mathrm{L}$} & Mean & 4.57 & 4.38 & 4.22 & 3.77 & 6.90 & 5.66 & 4.91 & 5.18 \\
\hline & $\mathrm{SD}$ & 1.24 & 1.07 & 0.51 & 0.81 & 1.68 & 1.57 & 1.52 & 1.41 \\
\hline & JJ & 3.98 & 3.01 & 3.17 & 3.12 & 5.01 & 4.00 & 3.68 & 3.78 \\
\hline & $\mathrm{TL}$ & 5.40 & 5.55 & 3.79 & 5.01 & 8.90 & 6.36 & 5.53 & 4.56 \\
\hline & JB1 & 4.70 & 4.65 & 3.91 & 3.72 & 7.78 & 6.75 & 4.97 & 5.65 \\
\hline & $\mathrm{CH}$ & 4.34 & 4.76 & 4.62 & 4.28 & 4.60 & 4.64 & 6.24 & 6.50 \\
\hline & PS & 5.72 & 4.54 & 3.83 & 3.59 & 7.39 & 5.97 & 5.33 & 4.56 \\
\hline & DM & 2.94 & 2.12 & 2.76 & 2.77 & 4. 61 & 3.38 & 3.60 & 3.20 \\
\hline & WL & 4.01 & 4.50 & 3.55 & 4.71 & 5.29 & 3.94 & 4.10 & 5.53 \\
\hline & $\mathbf{J B} t$ & 2.76 & 2.94 & 3.08 & 2.86 & 3.84 & 3.82 & 3.53 & 3.27 \\
\hline & Mean & 4.23 & 4.01 & 3.59 & 3.76 & 5.93 & 4.86 & 4.62 & 4.63 \\
\hline & SD & 1.05 & 1.17 & 0.58 & 0.84 & 1.83 & 1.31 & 1.03 & 1.19 \\
\hline
\end{tabular}

Appendix F.-Low Alcohol group: Dynamic and Static tracking error in arbitrary units under bright and dim illumination conditions.

\begin{tabular}{|c|c|c|c|c|c|c|c|c|c|}
\hline \multirow{2}{*}{$\begin{array}{l}\text { Level of } \\
\text { Illumination }\end{array}$} & \multirow[b]{2}{*}{ Subject } & \multicolumn{4}{|c|}{ Static } & \multicolumn{4}{|c|}{ Dynamic } \\
\hline & & Pre & 1-Hour & 2-Hour & 4-Hour & Pre & 1-Hour & 2-Hour & 4-Hour \\
\hline \multirow{8}{*}{$0.1 \mathrm{ft} . \mathrm{L}$} & $\mathrm{MG}$ & 8.68 & 6.60 & 5.54 & 4.43 & 11.28 & 12.06 & 9.34 & 7.90 \\
\hline & $\mathrm{BB}$ & 5.45 & 3.23 & 2.50 & 2.21 & $7.46^{*}$ & 6.57 & 3.23 & 3.21 \\
\hline & RK & 6.95 & 7.58 & 5.31 & 6.98 & 8.40 & 11.42 & 13.65 & 10.97 \\
\hline & LS & 5.70 & 4.31 & 5.15 & 2.67 & 8.07 & 7.67 & 5.93 & 4.84 \\
\hline & $\mathrm{FE}$ & 4.80 & 3.68 & 3.64 & 2.41 & 5.63 & 5.11 & 4.60 & 3.15 \\
\hline & $\mathrm{RF}$ & 4.05 & 2.60 & 2.76 & 1.65 & 5.99 & 5.04 & 3.97 & 3.22 \\
\hline & $C D$ & 2.69 & 2.93 & 2.93 & 2.55 & 4.44 & 4.22 & 3.49 & 3.25 \\
\hline & $\mathrm{PD}$ & 3.15 & 3.23 & 2.86 & 2.44 & 6.00 & 5.63 & 5.33 & 3.43 \\
\hline \multirow{12}{*}{$1.0 \mathrm{ft} . \mathrm{L}$} & Mean & 5. 18 & 4.27 & 3.84 & 3.17 & 7.16 & 7.22 & 6.19 & 5.00 \\
\hline & SD & 1.98 & 1.83 & 1.28 & 1.74 & 2.13 & 2.99 & 3.58 & 2.91 \\
\hline & $\mathrm{MG}$ & 7.72 & 7.03 & 5.58 & 3.21 & 7.01 & 8.20 & 7.84 & 5.61 \\
\hline & $\mathrm{BB}$ & 2.95 & 2.72 & 1.82 & 2.27 & 4.48 & 4.48 & 3.31 & 2. 46 \\
\hline & RK & 7.10 & 6.67 & 5.80 & 5.09 & 7.50 & 6.27 & 7.10 & 6. 49 \\
\hline & LS & 4.74 & 5.20 & $3.94^{*}$ & 3.34 & 5.71 & 6.66 & 4. $75^{*}$ & 4.47 \\
\hline & $\mathrm{FE}$ & 3.71 & 3.38 & 3.14 & 2.25 & 4.67 & 5.04 & 4.44 & 2.31 \\
\hline & $\mathrm{RF}$ & 3.30 & 3.41 & 2.54 & 2.23 & 3.86 & 4.50 & 3.11 & 3.17 \\
\hline & CD & 2.64 & 2.53 & 2.51 & 2.43 & 3.25 & 4.07 & 3.66 & 3.30 \\
\hline & $\mathrm{PD}$ & 5.87 & 3.45 & 3.19 & 3.27 & 6.39 & 4.90 & 3.58 & 3.27 \\
\hline & Mean & 4.75 & 4.30 & 3.56 & 3.01 & 5.36 & 5.52 & 4.72 & 3.88 \\
\hline & $\mathrm{SD}$ & 1.94 & 1.77 & 1.45 & 0.97 & 1.53 & 1.41 & 1.79 & 1.51 \\
\hline
\end{tabular}

*Approximate score due to recording problem. 
APPEnDix G.-Moderate Alcohol group: Dynamic and static tracking error in arbitrary units under bright and dim $\cdot$ illumination conditions.

\begin{tabular}{|c|c|c|c|c|c|c|c|c|c|}
\hline \multirow{2}{*}{$\begin{array}{l}\text { Level of } \\
\text { Illumination }\end{array}$} & \multirow[b]{2}{*}{ Subject } & \multicolumn{4}{|c|}{ Static } & \multicolumn{4}{|c|}{ Dynamic } \\
\hline & & Pre & 1-Hour & 2-Hour & 4-Hour & Pre & 1-Hour & 2-Hour & 4-Hour \\
\hline \multirow{10}{*}{$0.1 \mathrm{ft} . \mathrm{L}$} & BT & 4.35 & 4.35 & 4.17 & 3.12 & 4.99 & 8.92 & 6.45 & 4.71 \\
\hline & $\mathrm{GE}$ & 5.52 & 3.97 & 4.78 & 3.82 & 7.44 & 14.17 & 10.29 & 7.12 \\
\hline & FS & 3.65 & 3.85 & 3.80 & 3.14 & 4.46 & 8.91 & 8.45 & 4.49 \\
\hline & VH & 6.63 & 6.53 & 5.24 & 4.73 & 7.23 & 12.48 & 8.95 & 6.59 \\
\hline & $\mathbf{L} \mathbf{J}$ & 8.11 & 6.51 & 4.99 & 3.79 & 7.83 & 11.18 & 8.25 & 5.90 \\
\hline & BS & 6.26 & 5.01 & 4.37 & 4. 43 & 7.52 & 7.13 & 6.36 & 5. 56 \\
\hline & $\mathrm{FG}$ & 3.40 & 4.66 & 3.76 & 3.10 & 6.39 & 10.51 & 5.31 & 7.71 \\
\hline & $\mathrm{JM}$ & 5.21 & 5.24 & 5.72 & 4.33 & 7.43 & 14.64 & 12.12 & 7.76 \\
\hline & Mean & 5.39 & 5.02 & 4.60 & 3.81 & 6.66 & 10.99 & 8.27 & 6.23 \\
\hline & $\mathrm{SD}$ & 1.60 & 1.04 & 0.70 & 0.65 & 1.27 & 2.66 & 2.24 & 1.27 \\
\hline \multirow{10}{*}{$1.0 \mathrm{ft.} \mathrm{L}$} & BT & 3.51 & 3.19 & 4.15 & 3.14 & 4.29 & 5.72 & 6.57 & 3.61 \\
\hline & $\mathrm{GE}$ & 2.58 & 3.90 & 3.88 & 3.15 & 4.42 & 7.97 & 6.87 & 5.43 \\
\hline & FS & 4.18 & 3.90 & 3.38 & 3.00 & 6.15 & 7.01 & 4.86 & 3.63 \\
\hline & $\mathrm{VH}$ & 5.40 & 6.62 & 6.39 & 3.83 & 8.33 & 11.73 & 8.84 & 6.57 \\
\hline & $\mathrm{LJ}$ & 8.01 & 7.43 & 3.99 & 3.53 & 6.80 & 9.23 & 5.37 & 5.05 \\
\hline & BS & 4.53 & 4.20 & 4.50 & 3.90 & 5.89 & 6.26 & 4.85 & 4.28 \\
\hline & $\mathbf{F G}$ & 6.01 & 4. 10 & 3.90 & 4.70 & 6.77 & 5.58 & 4.05 & 5.25 \\
\hline & $\mathrm{JM}$ & 6.30 & 6.07 & 5.64 & 4.09 & 6.34 & 9.63 & 6.67 & 4.96 \\
\hline & Mean & 5.06 & 4.93 & 4. 48 & 3.67 & 6.12 & 7.89 & 6.01 & 4.85 \\
\hline & $\mathrm{SD}$ & 1.73 & 1.55 & 1.02 & 0.58 & 1.32 & 2.17 & 1.53 & 0.99 \\
\hline
\end{tabular}


